\title{
Organizational characteristics and processes are important in the adoption of the Alberta Nutrition Guidelines for Children and Youth in child-care centres
}

\author{
Anna P Farmer $1,2, *$, Hara Nikolopoulos ${ }^{1}$, Linda McCargar ${ }^{1}$, Tanya Berry ${ }^{3}$ and \\ Diana Mager ${ }^{1,4}$ \\ ${ }^{1}$ Department of Agricultural, Food and Nutritional Science, University of Alberta, Edmonton, Alberta, Canada: \\ ${ }^{2}$ Centre for Health Promotion Studies, University of Alberta, Edmonton Clinic Health Academy, 4-370, Edmonton, \\ Alberta, T6G 2P5, Canada: ${ }^{3}$ Faculty of Physical Education and Recreation, University of Alberta, Edmonton, Alberta, \\ Canada: ${ }^{4}$ Department of Pediatrics, University of Alberta, Edmonton, Alberta, Canada
}

Submitted 10 April 2013: Final revision received 3 July 2014: Accepted 7 August 2014: First published online 22 0ctober 2014

\begin{abstract}
Objective: The objective of the present study was to gain an understanding of the organizational characteristics and processes in two child-care centres that may influence adoption of the Alberta Nutrition Guidelines for Children and Youth (ANGCY).

Design: In-depth qualitative case studies. Data were collected through direct observations, key informant interviews and field notes. Diffusion of Innovations theory guided the evaluation and intrinsic case analysis.

Setting: Two urban child-care centres in Edmonton, Alberta, Canada identified as exemplary early adopter cases.

Subjects: Ten key informants comprised of directors, junior and senior staff members participated in interviews.

Results: Organizational processes such as leadership, networking and knowledge brokering, health champions and organizational culture positively influenced adoption behaviour in child-care centres. A key determinant influencing organizational behaviour within both centres was the directors' strong leadership. Acceptance of and adherence to the guidelines were facilitated by organizational factors, such as degree of centralization, formalization and complexity, level of staff training and education. Knowledge brokering by directors was important for transferring and exchanging information across the centre. All child-care staff embraced their informal role as health champions as essential to supporting guideline adherence and encouraging healthy food and eating environments.

Conclusions: Organizational processes and characteristics such as leadership, knowledge brokering and networking, organizational culture and health champions played an important role in the adoption of nutrition guidelines in child-care centres. The complex interplay of decision making, organization of work and specialization of roles influenced the extent to which nutrition guidelines were adopted.
\end{abstract}

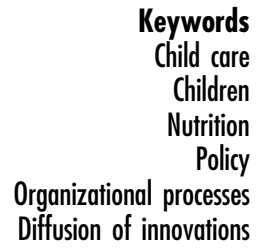

Keywords

Child care

Policy

Diffusion of innovations
Institutional nutrition policies for children are emerging as an approach to ensure children have access to healthy and nutritious food choices. With an increasing use of child care in Canada, implementation of nutrition guidelines for children is important as early childhood is a time when children are establishing good eating habits. Although there is sufficient evidence to support that early nutrition affects long-term health, little is known about the effect that nutrition policies and guidelines have on behaviours in the food environment.
In 2002-2003, 54\% of Canadian children aged 6 months to 5 years were in non-parental child care of some type, such as day-care centres ${ }^{(1)}$. Children in child care may consume up to one-half to two-thirds of their total daily food requirements at the child-care centre ${ }^{(2)}$. Alberta was one of the first provinces in Canada to have nutrition guidelines for children and youth. In June 2008, the Alberta Government distributed print and electronic formats of the Alberta Nutrition Guidelines for Children and Youth (ANGCY) to child-care centres, schools and 
recreational facilities ${ }^{(3,4)}$. Organizations and facilities have the option of implementing the nutrition guidelines because the guidelines are non-mandatory. Although adoption of the guidelines is optional, organizations are encouraged to implement them to whatever extent is possible. The ANGCY provides general recommendations for healthy eating in three areas: (i) healthy diets for children and youth; (ii) enhancing access to safe nutritious foods; and (iii) creating environments that support healthy food choices. In addition to the healthy eating recommendations, organizations are encouraged to adopt the Food Rating System as a simple way to separate healthy foods from unhealthy foods ${ }^{(3,4)}$. The Food Rating System is based on three food categories: (i) 'choose most often'; (ii) 'choose sometimes'; and (iii) 'choose least often'(3). The foods identified in each category were classified by their nutritional value based on the amount of fat, cholesterol, sodium, fibre, sugar, protein, vitamins and minerals, and artificial sweeteners ${ }^{(3)}$. The ANGCY is also an educational resource that provides practical examples of ways to implement the guidelines (e.g. serving size, sample menus) and to create healthy food environments (e.g. child-size utensils, role modelling).

Organizational behaviour literature examining how a technical or social innovation such as adoption of a policy spreads across organizations has been dominated by the Diffusion of Innovations (DoI) theory ${ }^{(5)}$. Some diffusion research has examined what characteristics distinguish organizations that adopt innovations from those that do not, and has shown a positive relationship between organizational factors and the adoption behaviour of an innovation ${ }^{(6,7)}$. DoI theory is used to understand organizational characteristics and behaviour and to provide a framework for examining factors that may influence adoption and maintenance of new practices, such as health policies ${ }^{(8)}$. It also attempts to understand how and why innovations diffuse across organizations by examining structural characteristics such as centralization (the degree to which authority in an organization is concentrated in only a few individuals), formalization (the degree to which an organization emphasizes following rules and procedures), complexity (the degree of specialization of job roles) and organizational innovativeness (e.g. leadership, networking) of organizations ${ }^{(8)}$. Although only a few studies have highlighted the influence of contextual factors on the process of diffusion of an innovation in organizations, consideration of such organizational factors is often overlooked ${ }^{(9,10)}$. More research is required to understand the influence of organizational factors such as structural characteristics, leadership and environment on adoption behaviour ${ }^{(7)}$. There are no other studies that have examined the extent to which organizational processes and characteristics influence the uptake of nutrition guidelines in child-care settings. Thus, the purpose of the present, exploratory qualitative study was to gain an in-depth understanding of the organizational characteristics and processes that may influence the adoption and implementation of the ANGCY in two childcare centres in Edmonton, Alberta.

\section{Study design}

A qualitative, multiple-case, exploratory study design was used to explore two exemplary cases ${ }^{(10,11)}$. Exploratory case study is an appropriate design for understanding contextual factors and processes involved in adopting a specific innovation $^{(11)}$. Multiple data collection methods were used to enhance the confirmability of the data ${ }^{(12,13)}$. Direct observations, field notes and interview data were coded and triangulated to give credibility to the findings ${ }^{(11-13)}$.

The present qualitative study was part of Phase 2 of an evaluation framework of The Alberta Nutrition Guidelines Outcomes (TANGO) study that evaluated the implementation of the ANGCY in schools, child-care and recreational facilities ${ }^{(14,15)}$. In Phase 1 of TANGO, awareness of and intention to use the guidelines were assessed in 488 child-care centres in Alberta, Canada using a telephone-based survey. The Stages of Change constructs guided the survey ${ }^{(16)}$, which addressed key concepts related to awareness, adoption and barriers to implementing the guidelines in child-care facilities ${ }^{(8)}$.

\section{Sampling}

Two urban child-care centres in Edmonton, Alberta, identified as 'early adopters' of the ANGCY, were assessed. Only urban child-care centres were considered as a way to limit the geographical space between the cases and to understand the uniqueness of urban child-care centres, which may differ from rural centres. 'Early adopters' were defined as centres that implemented some aspect of the strategies outlined in the ANGCY (e.g. healthy eating) within one year of receiving the guidelines. Early adopter organizations were selected because they could provide insight into which organizational practices may have facilitated early adoption of the guidelines. Purposeful sampling of exemplary cases was based on the adopter characteristics identified in Phase 1 from a sub-sample ( $n$ 101) of child-care centres. Inclusion criteria used in the initial screening included: (i) made changes to the nutritional quality of foods as a result of the ANGCY; (ii) implemented changes for at least 6 months; and (iii) provided consent for follow-up in Phase 1. This reduced the sample from 101 to sixty-six. In the second screening, the eligible centres had to provide all meals/ snacks and adhere closely to the guideline recommendations, reducing the number from sixty-six to twenty-seven. In the final level of screening, the centres that most closely adhered to the ANGCY based on an evaluation by the research team reduced the number of eligible centres from twenty-seven to six. 


\section{Access and recruitment}

The research team contacted the six eligible urban childcare centres and two of them agreed to participate in the study. Directors and staff from each child-care centre consented to participate prior to the start-up of the study. To ensure a comprehensive perspective, the selection of key informants was based on key positions that staff held in the centre (i.e. directors, cooks) and their level of experience.

\section{Theoretical framework}

DoI theory ${ }^{(8)}$ guided the evaluation and analysis of the results. Key organizational characteristics considered in the adoption of innovations were: (i) centralization (i.e. the degree to which authority in an organization is concentrated in only a few individuals); (ii) formalization (i.e. the degree to which an organization emphasizes following rules and procedures); (iii) complexity (i.e. the degree of specialization of job roles); and (iv) organizational innovativeness (i.e. leadership, networking).

\section{Data collection}

Data were collected by a researcher (H.N.) through direct observations, key informant interviews and field notes. The data from the three sources were analysed separately, and together, and then compared to ensure trustworthiness and to limit investigator bias ${ }^{(12,13)}$. At each site, direct observations occurred on days specified by the centres and at the same time of the day and meal. Ideally, unannounced visits would have enhanced the credibility of the data collected; however, each site requested notification prior to visits. Direct observations were systematically recorded with the use of an observational tool ${ }^{(17)}$ that was modified by the research team. Field notes recorded at each site included observations on general attitudes of children and child-care workers at mealtimes, child-care workers' behaviours related to adherence to the guidelines and the organizational procedures.

Ten semi-structured key informant interviews (30-65 min) were conducted with directors, junior and senior staff members at each centre (see Appendix, interview protocol). The interview protocol was guided by the DoI framework focusing on organizational characteristics: (i) organizational structure, operating procedures, processes and strategies used in adoption and implementation of the guidelines; and (ii) perceptions of and attitudes towards content, adoption and usability of the guidelines.

\section{Data analysis}

Interviews were digitally recorded, transcribed verbatim and coded by two researchers (H.N., A.P.F.). Transcript quality was validated using the methods suggested by Poland $^{(18)}$ and reviewed by an external researcher (N.M.). NVivo software version 9 was used to organize and manage the qualitative data, including thematic analysis and conceptual ordering ${ }^{(13)}$. Thematic analysis and conceptual ordering of the data were conducted by a researcher (H.N.) and reviewed by the research team ${ }^{(13)}$. Due to the nature of data sources, both inductive and deductive coding strategies were used to analyse the content. Procedures and methods were corroborated and verified by senior research team members (A.P.F., D.M.). An external qualitative researcher (N.M.) independently reviewed the interview data for credibility and dependability of interpretations. Direct observations, field notes and interview data were triangulated to enhance credibility and confirmability of findings ${ }^{(11-13)}$.

\section{Description of cases}

The child-care centres were accredited ${ }^{(19)}$, urban childcare institutions that have been operating for over 20 years. Each case had a similar organizational structure and operated with a top-down managerial approach (Table 1).

Case 1 was a publicly owned, non-profit child-care centre comprised of a Board of Directors that included community members and parents. The Board of Directors was responsible for decisions related to the administration and management of the centre and utilized a participatory approach to decision making. The Executive Director (ED) reported to the Board of Directors, supervised staff (i.e. Early Childhood Educators (ECE), cook and volunteers) and was responsible for the centre's daily operations. The delivery of the children's programmes was dependent on the integration of volunteers on a daily basis. The centre had a kitchen facility and employed a full-time cook.

Case 2 was a privately owned, for-profit child-care centre, comprised of a Director-Owner at the helm of the organization who supervised the Assistant Director (AD) and staff (i.e. ECE, parent volunteers). In contrast to Case 1, the Director-Owner serves as ED and retained authority and decision making. This case used a traditional top-down approach to execute authority ${ }^{(20)}$ and the ED sought input from staff on minor issues (e.g. acceptability of menu items). Unlike Case 1, the ED had a dual role as administrator and cook, and shared some of these responsibilities with the AD, who also was employed as an ECE. Given the dual nature of their roles, they had a limited amount of time to attend to administrative tasks compared with the ED in Case 1.

The child-care centres were similar in size (forty-seven and sixty children) and employed twelve and eleven employees, respectively, providing a 5:1 ratio of children to caregivers. Case 1 cared for toddlers and older children (i.e. 19 months to 6 years), while Case 2 cared for infants and older children (i.e. 3 months to 6 years). Child-care staff in Case 1 were more highly trained and had a two-year ECE diploma, whereas staff in Case 2 had a $50 \mathrm{~h}$ child-care assistant course. Case 2 had slightly more children (60 v. 47) and included children who were younger (3 months $v .19$ months). 
Table 1 Description of the two child-care centres

\begin{tabular}{lll}
\hline & Case 1 & Case 2 \\
\hline Date of establishment & 1986 & 1991 \\
Organizational type & Non-profit day care & Private day care \\
Organizational structure & Top-down/horizontal & Top-down \\
Accredited & Yes & Yes \\
Location & Urban & Urban within walking distance \\
Proximity to grocery store & Not within walking distance & No \\
Vending machines & No & 60 \\
Number of children & 47 & $5: 1$ \\
Average ratio of children to staff observed & $5: 1$ & 3 months-6 years \\
Age range of children & 19 months-6 years & 11 \\
Number of staff & 12 & One periodically \\
Number of volunteers & One per day & No (Director is the cook) \\
Cook & Yes & Yes \\
Kitchen & Yes & Min. Level 1 Childcare \\
Level of formal training of staff & Min. 2-year diploma in Early & Assistant Course (50 h) \\
Requirements for professional & Childhood Education & $1 /$ year
\end{tabular}

\section{Results and discussion}

\section{Internal characteristics of organizational structure: degree of centralization, formalization and complexity}

The internal characteristics of the organizational structure that related to the degree of centralization, complexity, formalization and interconnectedness differed between the two cases. Both the organizational structure and the strategies used to implement the nutrition guidelines differed between the cases whereas organizational processes were similar. Case 1 functioned as a non-profit organization while Case 2 was a for-profit business.

Case 1 operated with a low degree of centralization and a high degree of formalization and complexity. High complexity and formalization were practised by employing auxiliary staff (i.e. cook and administrative assistant), which influenced the standardization of job roles and the amount of time spent and commitment to tasks ${ }^{(6)}$. Authority in Case 1 was dispersed among many members of the organization (i.e. low centralization) and there was greater standardization and specialization of roles (i.e. high formalization and complexity), which is a typical characteristic of non-profit organizations. As well, there was more consultation with parents and staff members at all levels of the organization in Case 1 compared with Case 2. Including parents and experts along with a Board of Directors can influence operating procedures of organizations by offering a wider breadth of knowledge and support to the overall functioning of an organization ${ }^{(21)}$. A previous study found that an organization with a lower degree of centralization was associated with lower innovativeness while a higher degree of formalization and complexity were associated with a higher likelihood of adoption of an innovation ${ }^{(8)}$. In contrast to these findings, Case 2 operated with a high degree of centralization and a low degree of formalization and complexity. Similar to another study, Case 2's authority and decision making were centralized to the ED (i.e. high centralization), and it had lower standardization and specialization of roles (i.e. low formalization and complexity) ${ }^{(8)}$.

An organization is more likely to be reactive than proactive when it has a higher degree of centralization and a lower level of formalization, and complexity is more likely to be reactive than proactive ${ }^{(20,21)}$. In the present study, Case 2 staff spent more time multi-tasking than Case 1 staff which meant there was less time to cover administrative tasks. Given the organizational structure and availability of resources, such as having more highly trained and skilled staff and more flexibility to dedicate time to other activities, Case 1 had greater capacity for being proactive and creative in implementing the nutrition guidelines. A higher degree of adoption of the guidelines in Case 1 may be explained, in part, by the differences in organizational factors, such as the degree of centralization, the organization of work and the specialization of roles. The degree of adoption of the ANGCY in Case 2 may have been constrained by the lower ratio of staff to children coupled with caring for children aged 3 months to 6 years old, compared with Case 1 where staff were minding children aged 19 months and older. The demands of caring for infants with fewer staff may have precluded the centre's ability to implement additional health promotion activities beyond providing basic care. As well, a lower ratio of staff to children may be more likely in a for-profit compared with a non-profit child-care setting. These findings were consistent with other literature reporting differences in organizational structure between non-profit and for-profit day-care centres across Canada ${ }^{(22)}$. Similar to the present study, other non-profit centres were more formalized, more complex and less centralized than for-profit centres, affecting employment of auxiliary staff, 
time spent on tasks, involvement of parents in decision making, and clearly articulated policies and procedures resulting in higher quality of care ${ }^{(22)}$.

\section{Organizational processes}

Organizational culture and processes, including leadership, networking, knowledge brokering and health champions, played key roles in the innovativeness of the organizations and their adoption behaviour (Table 2).

\section{Organizational culture}

In the present study, organizational culture was a key determinant in the adoption and implementation of the ANGCY. Organizational culture refers to the practices, norms and values of an organization ${ }^{(21)}$. The business literature suggests that a positive organizational culture is the key to producing returns but it is the attitude and motivation of leaders that create and maintain the culture of the organization $^{(23)}$. Other work, as well as the present study, found that ED set the tone of their organization and are instrumental in establishing and maintaining the values and norms of the organization through their own actions ${ }^{(21)}$. A leader's motivation and attitude was reported to be the strongest predictor of adoption of innovations in organizations and leaders not only affect decisions to adopt an innovation, but also are instrumental in creating and maintaining the culture within an organization which affects implementation ${ }^{(22)}$.

The ED from Case 1 describes how the centre makes decisions and the culture of the organization:

'...actually, we ah, is everybody's input together. Like we discuss with each other before we make final decision - what is especially going to affect the staff and children. It's not like I just make a decision and here it is.' (May 2011)

\section{Leadership}

In the present study and other studies, strong leadership was another key determinant that appeared to influence organizational behaviour ${ }^{(20,21)}$. Strong leaders lead by example and support desired practices by subsequently fostering a positive culture within the organization ${ }^{(21)}$. Staff in the present study described a good leader as one who acted as a health champion; recognized their role; was accountable, approachable and supportive; and provided regular feedback to staff. Furthermore, a strong leader was described by staff as being available and able to provide guidance and advice on issues of concern. It was also

Table 2 Factors influencing adoption and implementation of the Alberta Nutrition Guidelines for Children and Youth (ANGCY) in the two child-care centres

\begin{tabular}{|c|c|}
\hline Process & Outcome \\
\hline $\begin{array}{l}\text { Leadership } \\
\text { - Role recognition } \\
\text { - Trust } \\
\text { - Accountability } \\
\text { - Approachable } \\
\text { - Supportive } \\
\text { - Feedback }\end{array}$ & $\begin{array}{l}\text { - Staff feel there is a leader in the centre and feel they have someone to turn to for direction/ } \\
\text { guidance when problems/issues arise } \\
\text { - Staff trust leadership to make the best decisions for the centre } \\
\text { - Provide staff with informed solutions best for all involved } \\
\text { - Staff feel comfortable to approach Directors with problems/issues as they arise } \\
\text { - Staff feel supported by Directors both in practice and in raising issues/ideas } \\
\text { - Regular feedback provided to staff both formally (performance evaluations annually) and } \\
\text { informally (conversations/discussions) as issues arise }\end{array}$ \\
\hline $\begin{array}{l}\text { Networking and knowledge brokering } \\
\text { - Information seeking/sharing through } \\
\text { social networks } \\
\text { - Transferring and exchanging } \\
\text { information }\end{array}$ & $\begin{array}{l}\text { - Information sharing both formally (staff meetings) and informally (passing conversation/ } \\
\text { discussions or informal meetings as issues arise) } \\
\text { - Active networking of local, provincial, national networks where members meet to hold } \\
\text { discussions, share knowledge/information and generate new ideas/solutions } \\
\text { - Creates awareness } \\
\text { - Acts as a support to the organization } \\
\text { - Provides opportunities to share ideas } \\
\text { - Facilitates decision making and finding solutions to problems } \\
\text { - Critical to communication of the ANGCY across the child care }\end{array}$ \\
\hline $\begin{array}{l}\text { Organizational culture } \\
\text { - Teamwork } \\
\text { - Information sharing } \\
\text { - Collaboration } \\
\text { - Supportive environment } \\
\text { - Value }\end{array}$ & $\begin{array}{l}\text { - All staff members work together to achieve best practice } \\
\text { - Staff share knowledge, ideas, and collaborate with one another } \\
\text { - Staff trust and feel supported by one another } \\
\text { - Staff feel highly valued in the organization } \\
\text { - High social capital }\end{array}$ \\
\hline $\begin{array}{l}\text { Health champions } \\
\text { - Role in the adoption of the ANGCY }\end{array}$ & $\begin{array}{l}\text { - Enhance understanding of healthy eating and child development } \\
\text { - Improve the healthy eating environment of the child care } \\
\text { - Increase capacity of child care to support healthy eating environment } \\
\text { - Advocate on behalf of children } \\
\text { - Promote health and well-being of children }\end{array}$ \\
\hline
\end{tabular}


important for a leader to provide formal and informal feedback to staff which was helpful for building staff confidence and trust, which in turn appeared to enhance staff commitment to the organization.

As one staff member, Melissa* from Case 1, describes:

'...Yeah. Yeah. From Mrs Darcy*, you know this, she always appreciate[s] whatever we do she always appreciate[s] and plus we really like it here...' (March 2011)

Moreover, a good leader was reported as one who made the best decisions for the good of the centre and helped staff with informed solutions. The staff in the present study reported that effective and strong leadership was essential for the successful adoption of an innovation, such as the nutrition guidelines. Another study reported that regular and timely feedback was beneficial as it increases the chances of successful implementation of an innovation ${ }^{(22,23)}$. It was evident that in each case in the present study, the ED's strong leadership positively shaped the organizational culture. Other organizational attributes, such as teamwork, information sharing, collaboration, supportive environment and staff perceptions of being a valued staff member, together contributed to building the centres' organizational culture.

\section{Networking}

Child-care staff in the present study acknowledged that having good communication and well-established social networks were crucial elements of a highly functioning organization and the ANGCY. As well, the social networking efforts exerted by the ED in the study cases provided staff with opportunities to share knowledge and generate ideas, and form new connections with local and national organizations. Related studies also reported that support and communication were key factors for the successful implementation of school nutrition policies in Canada $^{(24-28)}$. The ED regularly engaged in professional networks (e.g. at a community and provincial level) which functioned as a professional forum: to share ideas, expertise and information; to discuss new information and current issues and concerns; and to serve as a support system for achieving common goals. This is consistent with health-care literature which shows that diffusion was radically affected by inter-professional relationships ${ }^{(29)}$. It was through these social networks that ED were made aware of the nutrition guidelines and they, in turn, communicated this information to their staff.

As one ED describes from Case 1:

'We meet and we share information so if we have issues about maybe how much we are budgeting for our food, where we are going to be buying our food, the kinds of menus we're developing... that kind of discussion goes on.' (October 2010)

\footnotetext{
* Not actual name
}

\section{Knowledge brokering}

Knowledge brokering by the ED served an important role for transferring and exchanging information across the centres. Knowledge brokers are people who connect producers and users of knowledge by discovering reliable sources of information and making it accessible to those who need $\mathrm{it}^{(30)}$. The ED played a critical role in knowledge brokering with centre staff and they, in turn, relied on each other and especially on the ED for answers/solutions. It is important for staff to have access to a reliable and credible source of information to ensure continuity in health messaging, all of which can be facilitated by a knowledge broker.

Another staff member, Bonnie* from Case 2, describes:

'...definitely... I will ask the question here in the office... And they [referring to the ED] will sort of, like [do] more research about that... And they will support, you know, try to find what is the recent guidance, or what, how, how we can facilitate that.' (January 2011)

\section{Health champions}

Health champions had a role to play in the adoption of the ANGCY in the child-care centres in the present study. Health champions were also found to be a significant determinant in the adoption of nutrition guidelines in schools ${ }^{(31,32)}$. The ED's and staff's commitment to and understanding of healthy child development and the role of healthy eating were pivotal elements in the adoption of the guidelines and to the staff's identity as health champions. Staff identified their role as health champions as important and they felt that it was not the sole responsibility of one person but it was everyone's obligation to become health champions to promote the health and wellbeing of the children.

Another staff member, Donna* from Case 1, describes her role as a health champion was a team effort:

'...I think it's a team effort. I don't think any one person is, I think like it's kind of, umm, common sense. Like, I don't know, maybe it's just you don't think about it because it's just like easy [laughs] to, to do. And, we all, we all try to do it and we all, umm, work towards, like the kids are supposed to have, like always eat, like you have to say, "two or three vegetables" or whatever and so they have to pick. They don't, you don't say "do you want vegetables" cause then they'll usually say no [laughs]...' (January 2011)

\section{Implementation strategies}

It is well established that social and physical environments support healthy eating ${ }^{(23,24)}$. Through observations at the child-care centres and interviews, Case 1 implemented the ANGCY to a greater degree than Case 2 (Table 3). For instance, Case 1 had a more supportive healthy eating 
Table 3 Implementation strategies of the Alberta Nutrition Guidelines for Children and Youth (ANGCY) in the two child-care centres

\begin{tabular}{|c|c|c|}
\hline & Case 1 & Case 2 \\
\hline Role modelling & $\begin{array}{l}\text { - Yes: eat with children and eat same foods } \\
\text { - Staff can eat own food in staff room but not in } \\
\text { front of children }\end{array}$ & $\begin{array}{l}\text { - No: staff supervise } \\
\text { - Staff can eat own food in staff room but not in front of children }\end{array}$ \\
\hline Nutrition policy & $\begin{array}{l}\text { - Posted } \\
\text { - Strictly enforced (junk food not allowed on } \\
\text { site; made explicitly clear and upfront to } \\
\text { parents) } \\
\text { - Parents discouraged from sending food for } \\
\text { their children } \\
\text { - Junk food very limited at special events }\end{array}$ & $\begin{array}{l}\text { - Posted } \\
\text { - Mildly enforced (children are asked to put junk food in a bin where } \\
\text { they can pick it up on their way out but on occasion are allowed to } \\
\text { eat it; remind and ask parents not to send junk food if they see them) } \\
\text { - Parents are not discouraged from sending food for their children } \\
\text { - Junk food not limited at special events }\end{array}$ \\
\hline $\begin{array}{l}\text { Incorporate } \\
\text { nutrition into } \\
\text { curriculum }\end{array}$ & $\begin{array}{l}\text { - Yes: field trips, activities and educational } \\
\text { material } \\
\text { - Grocery store tours } \\
\text { - Farm and garden tours (e.g. Pumpkin } \\
\text { patch tour) } \\
\text { - Go to farmers' market } \\
\text { - Story time (Stone soup using veg. brought } \\
\text { from home) } \\
\text { - Nutrition alphabet bordering wall } \\
\text { - Counting exercises using pumpkin seeds }\end{array}$ & $\begin{array}{l}\text { - Very limited } \\
\text { - On occasion bake with children } \\
\text { - Taste testing 1-2 times/year }\end{array}$ \\
\hline $\begin{array}{l}\text { Priming/ } \\
\text { prompting }\end{array}$ & $\begin{array}{l}\text { Yes: clearly displayed throughout centre } \\
\text { - Guidelines are easily accessible to staff and } \\
\text { parents (available in main office) } \\
\text { - Menus posted } \\
\text { - Pictures of events/activities posted } \\
\text { throughout centre } \\
\text { - Food arrangements on display to coincide } \\
\text { with season/holiday/event (e.g. Thanksgiving) } \\
\text { - Nutrition alphabet bordering classrooms }\end{array}$ & $\begin{array}{l}\text { Yes: but limited } \\
\text { - Guidelines are easily accessible to staff and parents (post } \\
\text { guidelines in classrooms) } \\
\text { - Menus posted } \\
\text { - Post pictures of events but events very limited }\end{array}$ \\
\hline Inclusive & $\begin{array}{l}\text { Yes } \\
\text { - Parents are encouraged to have a voice in } \\
\text { major decision making for the centre } \\
\text { - Material available to parents }\end{array}$ & $\begin{array}{l}\text { No } \\
\text { - Parents are not included in decision making within the centre } \\
\text { - No material available pertaining to nutrition }\end{array}$ \\
\hline
\end{tabular}

environment than Case 2 by enforcing nutrition policies, incorporating nutrition into the curriculum, promoting awareness of healthy nutrition practices through positive role modelling and the use of priming and prompting. Nutrition policies in schools positively impact students' eating habits by limiting the availability of unhealthy foods sold in schools ${ }^{(33)}$. Incorporating nutrition in the curriculum and promoting awareness of healthy eating behaviours takes a multifaceted approach, thus increasing the likelihood of the uptake of nutritional guidelines ${ }^{(28-31)}$.

\section{Study strengths and limitations}

The present study is the first Canadian one in the child-care setting to report that organizational processes, such as leadership, organizational culture and networking, are relevant factors that may influence the adoption of nutrition guidelines. As well, it is the first study in a child-care setting to consider that adoption behaviour may be influenced by a complex interplay of internal organizational characteristics, such as the degree of centralization of decision making, complexity of the organization of work and specialization of roles, in two urban child-care centres in Alberta. Given that the present study purposefully sought early adopters of the guidelines, it is not surprising that they had many positive organizational attributes that promoted the early adoption and implementation of the guidelines.

Examination of early adopter cases only, to explore the uniqueness of each case, may limit transferability of the study's findings. However, the study was an exploratory case study and the purpose was to gain a greater understanding of the processes of adoption in each case. Also, limiting the geographical region of the cases was an attempt to understand the uniqueness of child-care centres in urban areas, which may differ from those in rural areas.

Future research should tailor evaluations specific to structural characteristics, implementation strategies and organizational processes of child-care organizations to gain a better understanding of the impact of these factors on the adoption behaviour of nutritional guidelines.

\section{Acknowledgements}

Acknowledgements: The authors are grateful to the participants who provided their time and commitment to this 
study. They are also grateful to Nicole McLeod (N.M.) for her assistance in reviewing the data. Financial support: This study was supported by research funds provided by the Canadian Institute of Health Research Population Health and research funds (to A.P.F.) provided by the Faculty of Agricultural, Life and Environmental Sciences and the School of Public Health at the University of Alberta. The Canadian Institute of Health Research had no role in the design, analysis or writing of this article. Conflict of interest: None. Authorship: This study is based on part of an MSc thesis submitted by H.N. to the University of Alberta, Canada. H.N., A.P.F. and D.M. conceptualized the study. H.N. and A.P.F. analysed the data and drafted the manuscript. A.P.F. revised all subsequent versions of the manuscript. A.P.F. and D.M. guided and supervised the study and assisted in interpretation of findings. L.M. and T.B. helped with interpretation of data and review the final draft. Ethics of buman subject participation: The study received ethics approval from the Research Ethics Board of the Faculties of Physical Education and Recreation, Agricultural, Life and Environmental Sciences and Native Studies at the University of Alberta.

\section{References}

1. Bushnik T (2006) Child Care in Canada. Catalogue no. 89-599-MIE2006003. Ottawa, ON: Statistics Canada.

2. Ball SC, Benjamin SE \& Ward DS (2008) Dietary intakes in North Carolina child-care centers: are children meeting current recommendations? J Am Diet Assoc 108, 718-721.

3. Alberta Health and Wellness (2008) Alberta Nutrition Guidelines and Resources for Healthy Eating. http://www. albertahealthservices.ca/2929.asp (accessed September 2013).

4. Alberta Health and Wellness (2008) Alberta Nutrition Guidelines for Children and Youth. http://www.healthy alberta.com/Documents/AB_Nutri_Guidelines_2008(1).pdf (accessed February 2011).

5. Greenhalgh T, Robert G, MacFarlane F et al. (2004) Diffusion of innovations in service organizations: systematic review and recommendations. Milbank $Q$ 82, 581-629.

6. Damanpour F (1991) Organizational innovation: a meta-analysis of effects of determinants and moderators. Acad Manage J 3, 555-590.

7. Damanpour F \& Schneider M (2006) Phases of the adoption of innovation in organizations: effects of environment, organization, and top manager. Br J Manage 17, 215-236.

8. Rogers EM (2003) Diffusion of Innovations, 4th ed., pp. 371-402. New York: The Free Press.

9. Cummings GG, Estabrooks CA, Midodzi WK et al. (2007) Influence of organizational characteristics and research utilization. Nurs Res 56, 4 Suppl, S24-S39.

10. Fitzgerald L, Ferlie E, Wood M et al. (2002) Interlocking interactions, the diffusion of innovations in health care. Hum Relations 55, 1429-1449.

11. Yin RK (2009) Case Study Research Design and Methods. Thousand Oaks, CA: SAGE Publications.

12. Lincoln YS \& Guba EG (1985) Naturalistic Inquiry. Newbury Park, CA: SAGE Publications.

13. Patton MQ (2002) Qualitative Research and Evaluation Methods, 3rd ed. Thousand Oaks, CA: SAGE Publications.

14. Downs SM, Anschetz CD, Quintanilha M et al. (2010) The 'Uptake' of the Alberta Nutrition Guidelines for Children and Youth by Childcare Facilities, Schools and Recreation Centres. Edmonton, AB: Canadian Nutrition Society.

15. Nikolopoulos H, Farmer AP, Berry TR et al. (2012) Perceptions of the characteristics of the Alberta Nutrition Guidelines for Children and Youth by child care providers may influence early adoption of nutrition guidelines in child care centres. Mat Child Nutr (Epublication ahead of print version).

16. Prochaska JO \& Velicer WF (1997) A transtheoretical model of health behavior change. Am J Health Promot 12, 38-48.

17. Miles MB \& Huberman AM (1994) Qualitative Data Analysis: An Expanded Sourcebook, 2nd ed., pp. 16-39. Thousand Oaks, CA: SAGE Publications.

18. Poland B (2003) Transcription quality. In Inside Interviews: New Lenses, New Concerns, pp. 628-650 [J Holstein and J Gubrium, editors]. Thousand Oaks, CA: SAGE Publications.

19. Alberta Children's Services (2002) Licensing Standards and Best Practices in Child Care. Edmonton, AB: Ministry of Children's Services.

20. Farmer AP (2007) Adoption of an innovation: the story behind preventive services in a community health centre. PhD Thesis, University of Toronto.

21. Downs SM, Farmer A, Quintanilha M et al. (2011) Alberta Nutrition Guidelines for Children and Youth: awareness and use in schools. Can J Diet Pract Res 72, 137-140.

22. Lyon ME, Young J, Canning PM et al. (2002) Organizational structure and behaviour in day care: differences between non-profit and for-profit centres. Can J Early Child Educ 9, 67 .

23. Cohen D \& Prusak L (2001) In Good Company: How Social Capital Makes Organizations Work. Boston, MA: Harvard Business School Press.

24. Skinner HA (2002) Promoting Health Through Organizational Change. San Fransisco, CA: Pearson Education Inc.

25. Littlejohns LB (2007) Passion and Policy: A Selected Review of Delivery Systems for Comprehensive School Health. Edmonton, AB: Ever Active Schools Program, Canada; available at http://www.everactive.org/uploads/files/ Documents/DeliverySystemsSchoolHealth.pdf

26. Veugelers P \& Schwartz ME (2010) Supportive environments for learning: healthy eating and physical activity within comprehensive school health. Can J Public Health 101, issue 8, S5-S8.

27. Ottem A (2008) An overview of school nutrition policies in Canada. Current Issues: The Inside Story, September issue. Toronto, ON: Dietitians of Canada; available at http:// livinghealthyschools.com/pdf/2008/Current_Issues2.pdf

28. Canadian Health Services Research Foundation (2003) The Theory and Practice of Knowledge Brokering in Canada's Health System. http://www.cfhi-fcass.ca/migra ted/pdf/Theory_and_Practice_e.pdf (accessed September 2013).

29. Stokols D (1992) Establishing and maintaining healthy environments. Toward a social ecology of health promotion. Am Psychol 47, 6-22.

30. Mullally ML, Taylor JP, Kuhle S et al. (2010) A provincewide school nutriton policy and food consumption in elementary school children in Prince Edward Island. Can J Public Health 101, 40-43.

31. MacLean LM, Clinton K, Edwards N et al. (2010) Unpacking vertical and horizontal integration: childhood overweight/ obesity programs and planning, a Canadian perspective. Implement Sci 5, 36.

32. Dietitians of Canada (2008) An Overview of School Nutrition Policies in Canada. Toronto, ON: Dietitians of Canada; available at http://www.dietitians.ca/DietitiansViews/Children-and-Teens/School-Nutrition-Policy.aspx

33. Quintanilha M, Downs S, Leiffers J et al. (2013) Factors and barriers with early adoption of nutrition guidelines in Alberta. J Nutr Educ Behav 45, 510-517. 


\section{Appendix}

\section{Interview Guide - child-care staff}

1. How long have you been working here?

a. What exactly do you do?

b. Do you enjoy your job?

2. I want to hear about your experience implementing the guidelines.

a. How did you first hear about the guidelines?

b. Are any social or professional networks available to you, i.e. health nurse, dietitian, etc.?

i. Yes, are you involved in any of those networks?

ii. Yes, can you please describe them for me? How they help you?

iii. Yes, did those contacts play a role in adopting or implementing the guidelines?

iv. No, would you like to have access to social networks?

3. Who first made the decision to adopt the guidelines?

a. How did you feel about that, i.e. adopting/ implementing the guidelines?

b. Do you believe in and agree with the content in the guidelines?

c. What are your responsibilities with respect to the guidelines?

d. Who makes those decisions?

4. I want to hear more about what you think about the guidelines.

a. How did the recommendations from the guidelines compare with what you were already doing? Better, worse, the same?

b. How do they fit in with what you were currently doing? With the curriculum?

c. What was your experience like translating the guidelines?

d. What was your experience like putting them into practice?

e. Did you notice any changes after implementing the guidelines? Can you please describe those changes for me?

i. In eating behaviour or the eating environment?
5. I want to hear more about your experience working with the guidelines.

a. What were the first things you did upon hearing about the guidelines?

b. Besides social contacts, were any other resources available to help with implementing the guidelines?

i. Budget, volunteers, nutrition training, etc.?

c. Was this a team effort? Was everybody involved?

d. Was there anything you found helpful?

e. Was there anything you found challenging?

6. Have you noticed any changes since putting the guidelines into practice?

a. Have the guidelines affected mealtimes in any way? How?

b. Have the guidelines affected grocery shopping in any way? How?

c. Has your behaviour changed as a result of working with the guidelines? How?

i. Eating, shopping, etc.?

d. Has the children's behaviour changed in any way? How?

i. Eating, requests, likes/dislikes?

e. Has the parent's behaviour changed in any way? i. How?

7. Is there anything we haven't covered that you feel is important to share with me? Administrators/ Directors ONLY

8. What are the structural characteristics of your organization? a. How many children attend this centre?

b. How many staff members and volunteers do have on a daily basis?

c. How are decisions made within the centre? i. Do they come from you, from the staff, or both?

ii. And, how are they carried out?

d. What is the level of formal training of the staff?

i. Are there any requirements to maintain professional knowledge?

ii. What opportunities are available to further their training?

e. What resources are available to your organization? i. Social networks, budget for nutrition, workshops, volunteers, etc. 